\title{
Seis espécies novas de Sphenorhina Amyot \& Serville (Hemiptera, Cercopidae, Tomaspidinae) ${ }^{1}$
}

\author{
Albino M. Sakakibara ${ }^{2}$ \\ Gervásio Silva Carvalho ${ }^{3}$
}

\begin{abstract}
Six new species of Sphenorhina Amyot \& Serville (Hemiptera, Cercopidae, Tomaspidinae). The following new species are described: Sphenorhina danielssoni sp.n. (from Peru, Huánuco), S. huggerti sp.n. (from Ecuador, Pichincha), S. unifasciata sp.n. (from Ecuador, Napo), S. pichita sp.n. (from Peru, San Ramon, Mina Pichita), S. badia sp.n. (from Ecuador, Azuay), and S. rubrolurida sp.n. (from Bolivia, Yungas del Palmar). New characters of male genitalia are considered in the generic definition.

KEY WORDS. Hemiptera, Cercopidae, Tomaspidinae, Sphenorhina, taxonomy
\end{abstract}

Dentre os espécimes de Tomaspidinae da coleção e também dos recebidos para identificação e estudo, provenientes do Museu Britânico (Londres), do Museu Lund, (Suécia), da Fundação e Instituto Miguel Lillo (Argentina), encontraram-se algumas espécies novas de Sphenorhina Amyot \& Serville, 1843 descritas a seguir.

As abreviaturas que aparecem no texto significam: (BMNH) The Natural History Museum, Londres, Inglaterra; (DZUP) Coleção de Entomologia Pe. J.S. Moure, Departamento de Zoologia, Universidade Federal do Paraná, Curitiba, Brasil; (IMLA) Fundación e Instituto Miguel Lillo, Tucumán, Argentina; (LUND) Museu Lund, Lund Universität, Suécia; (MCPU) Museu de Ciências e Tecnologia da Pontifícia Universidade Católica do Rio Grande do Sul, Porto Alegre, Brasil.

\section{Sphenorhina Amyot \& Serville, 1843}

Sphenorhina Amyot \& Serville, 1843: 562 (Espécie-tipo: Cicada rubra Linnaeus, 1758; desig. subseq.). -Fennah, 1968: 179.

Phytozamia Fennah, 1949: 610 (Espécie-tipo: Cicada rubra Linnaeus, 1758; desig. original). - Fennah, 1968: 179 (syn.).

FENNAH (1968) forneceu a seguinte caracterização para o gênero: "Pós-clípeo um tanto comprimido lateralmente, em perfil, retangular ou agudamente angulado distalmente; antenas com o terceiro artículo cônico, com a arista aproximadamente três vezes mais longa que o artículo. Tégminas em geral marrom-escuras e atravessadas por duas bandas largas vermelhas, alaranjadas, ou amarelas. Pigóforo

1) Contribuição número 1110 do Departamento de Zoologia, Universidade Federal do Paraná.

2) Departamento de Zoologia, Universidade Federal do Paraná. Caixa Postal 19020, 81531-990 Curitiba, Paraná, Brasil. Bolsista do CNPq.

3) Departamento de Biologia, Pontifícia Universidade Católica do Rio Grande do Sul. Caixa Postal 1429, 90619-900 Porto Alegre, Rio Grande do Sul, Brasil.

E-mail: gervasio@pucrs.br 
com as placas subgenitais longas, afiladas, agudas apicalmente, um processo espiniforme na margem externa de cada placa perto da base. Edeago moderadamente longo e usualmente com um delgado processo espiniforme, dirigido para cima, na sua margem posterior. Ovipositor com um par de lobos estreitos, digitiformes, na base das valvas-I, voltados para dentro, e um segundo par de processos que se encontram na linha mediana abaixo do par precedente, formados pela projeção da porção mediana distal dos valvíferos-I."

Acrescentam-se a essa definição, algumas outras características genéricas que foram observadas, tais como: pigóforo com um processo látero-posterior de cada lado, de forma mais ou menos alongada, digitiforme. Placa subgenital bipartida, cada parte apresentando, perto do ápice, pequenos espinhos, em geral enfileirados na margem externa, ou então isolados; o ápice da placa normalmente pontiagudo mas, em alguns casos, obtuso. Parâmeros bilobados distalmente, o lobo interno mais longo, digitiforme, curvado para fora, o lobo externo, mais basal, curto, curvado para baixo e para dentro, pontiagudo e fortemente pigmentado, em alguns casos bi-denticulado. Edeago em geral bi-ramoso (raramente uni-ramoso), disposto verticalmente; o ramo anterior afilado distalmente, algumas vezes obliquamente truncado; o ramo posterior mais curto, mais delgado, pontiagudo, mais ou menos paralelo ao anterior ou divergente.

\section{Sphenorhina danielssoni sp.n.}

Figs $1,7-10$

Diagnose. Coloração geral castanho-clara; tégminas com duas faixas tranversais esbranquiçadas; placa subgenital do macho com 2-3 pequenos espinhos nas margens externas perto do ápice; edeago com o ramo anterior levemente expandido no ápice e com microdenticulações.

Medidas (em milímetros), macho/fêmea. Comprimento total 11,68/11,70; largura da cabeça 2,00/2,12; largura do pronoto 3,28/3,32.

Holótipo macho (Fig. 1). Cabeça, pronoto, tórax inferiormente, pernas, abdômen, metade basal do escutelo e base das tégminas, castanho-claros; dois terços distais das tégminas castanho-escuros; duas faixas transversais, mais ou menos largas, de cor branco-marfim, atravessando as tégminas: a primeira na altura do ápice do escutelo, e a segunda na altura do ápice do clavo. Venação pouco distinta, com a porção reticulada bem evidente. Pigóforo (Fig. 7) com os processos láteroposteriores digitiformes, alongados, curvos para cima; placa subgenital bipartida, cada metade terminada em ponta aguda, tendo nos bordos externos, dois a três pequenos espinhos enfileirados; processos basais longos, afilados, pontiagudos, curvos para cima; parâmeros (Figs. 8-9) robustos, bilobados distalmente: lobo interno digitiforme, longo, aproximadamente cinco vezes mais longo que largo basalmente; lobo externo curto, curvado para baixo e para dentro, pontiagudo, fortemente pigmentado; edeago (Fig. 10) vertical, bífido, o ramo anterior alargado no meio, afilado distalmente, o ramo posterior pouco mais curto, afilado para o ápice e quase paralelo ao ramo anterior; em vista posterior, o ramo anterior com as bordas do gonóporo levemente expandidas e micro-denticuladas.

Fêmea. Semelhante ao macho. 

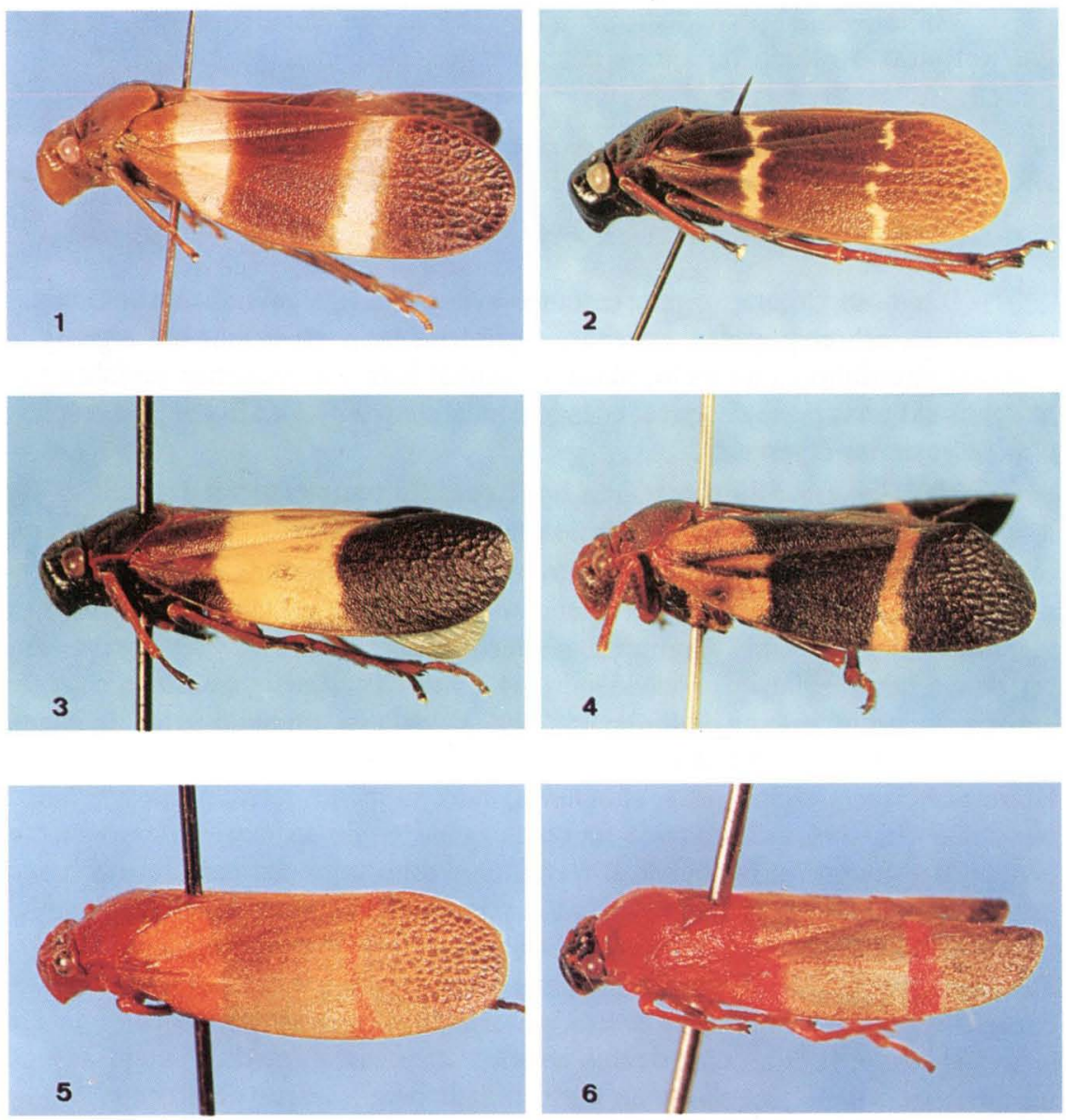

Figs 1-6. Espécies novas de Sphenorhina. (1) S. danie/ssoni (holótipo); (2) S. huggerti, parátipo fêmea; (3) S. unifasciata, holótipo; (4) S. pichita, holótipo; (5) S. badia, holótipo; (6) S. rubrolurida, holótipo.

Material examinado. Holótipo macho de "Peru: Huanuco, Tingo/ Maria 26.I.1984/ leg. L. Huggert", (LUND). Parátipo: 1 fêmea com os mesmos dados do holótipo, (DZUP).

Comentários. Esta espécie é quase inteiramente acastanhada. As tégminas apresentam duas faixas transversais esbranquiçadas, relativamente largas, uma na altura do ápice do escutelo (incluindo aproximadamente a metade do mesmo) e outra no terço apical, na altura do ápice do clavo. A placa subgenital, com cada uma das partes, terminada em ponta aguda e apresentando na margem lateral externa, pequenos espinhos enfileirados; o edeago com o ramo posterior um pouco mais curto e quase paralelo ao ramo anterior. 
Etimologia. Espécie dedicada a Roy Danielsson, curador do Museu Lund, que permitiu o estudo de vários homópteros neotropicais depositados naquele museu.

\section{Sphenorhina huggerti sp.n.}

Figs 2, 11-14

Diagnose. Coloração geral castanho-avermelhada; tégminas com duas faixas transversais esbranquiçadas, estreitas, a primeira mais ou menos em zig-zag, a segunda interrompida no meio; placa subgenital com 3-4 pequenos espinhos nas margens externas perto do ápice; edeago com o ramo anterior afilado para o ápice, o ramo posterior divergente.

Medidas em milímetros, macho/fêmea. Comprimento total 10,20/10,70; largura da cabeça 2,12/2,20; largura do pronoto 3,12/3,32.

Holótipo macho. Cabeça, exceto rostro, castanho-escura, quase preta; pronoto, tórax inferiormente, pernas, abdômen, escutelo, castanho-avermelhados; tégminas castanho-claras, levemente avermelhadas; duas faixas transversais estreitas, de cor branco-marfim, atravessando as tégminas: a primeira mais ou menos em zig-zag, na altura do ápice do escutelo, e a segunda na altura do ápice do clavo, interrompida no meio. Venação pouco distinta. Pigóforo (Fig. 11) com os processos látero-posteriores digitiformes, alongados, mais ou menos retos; placa subgenital bipartida, cada metade terminada em ponta aguda, tendo no bordo externo, quatro pequenos espinhos enfileirados, o basal mais robusto, e um espinho no bordo interno; processos basais longos, afilados, pontiagudos, curvos para cima; parâmeros (Figs. 12-13) robustos, bilobados distalmente: lobo interno digitiforme, longo, aproximadamente cinco vezes mais longos que largos basalmente; lobo externo curto, curvado para baixo e para dentro, pontiagudo, fortemente pigmentado; edeago (Fig. 14) bífido, vertical, com o ramo anterior levemente alargado no meio, afilado distalmente, o ramo posterior mais curto, afilado para o ápice e divergente.

Fêmea (Fig. 2). Semelhante ao macho.

Material examinado. Holótipo macho de "Ecuador: Pichin[cha]. Nono-/ Tandayapa road, 1900 m/27.II.1983/ leg. L. Huggert", (LUND). Parátipos: 2 fêmeas com os mesmos dados do holótipo, (LUND; DZUP); 1 fêmea de "Ecuador: Napo, Baeza/ 12-22.II.1983/ leg. L. Huggert", (LUND).

Comentários. Esta espécie é parecida com a anterior, diferindo principalmente nas seguintes características: a cabeça é castanho-escura, quase preta; as tégminas são mais escuras e com um toque avermelhado e as faixas claras bem mais estreitas, sendo a primeira mais ou menos em zig-zag e a segunda interrompida no meio ou em dois ou mais pontos; a placa subgenital, com cada uma das partes, terminada em ponta aguda e apresentando na margem lateral externa, pequenos espinhos enfileirados, o basal maior; na margem interna aparece também um espinho perto do ápice; o edeago apresenta o ramo posterior divergente.

Etimologia. A espécie é dedicada a L. Huggert, coletor dos exemplares estudados pertencentes ao Museu Lund. 


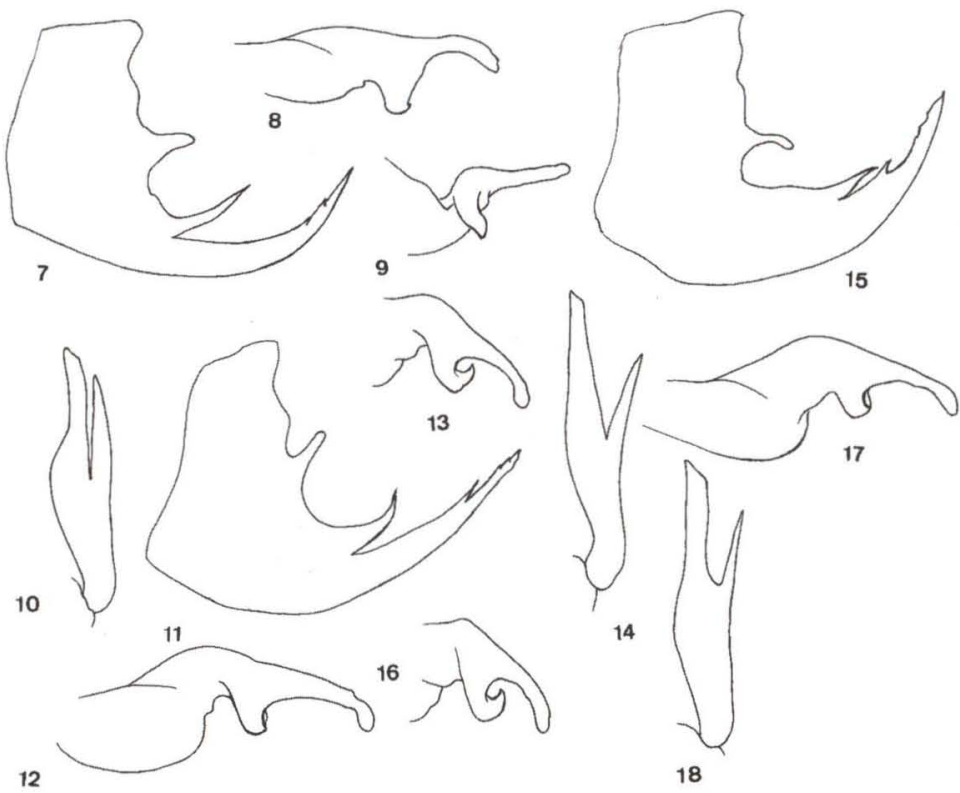

Figs 7-18. Genitálias dos holótipos. (7-10) S. danielssoni: (7) pigóforo; (8-9) ápice do parâmero esquerdo, em duas vistas; (10) edeago. (11-14) S. huggerti: (11) pigóforo; (12-13) ápice do parâmero esquerdo, em duas vistas; (14) edeago. (15-18) S. unifasciata: (15) pigóforo; (16-17) ápice do parâmero esquerdo, em duas vistas; (18) edeago.

\section{Sphenorhina unifasciata sp.n.}

Figs $3,15-18$

Diagnose. Coloração geral castanho-avermelhada; tégminas com uma faixa transversal mediana, larga, esbranquiçada; placa subgenital com três espinhos na margem externa, os dois distais diminutos, o basal bem maior; edeago com o ramo anterior afilado para o ápice, o ramo posterior afastado e divergente.

Medidas em milímetros, macho/fêmea. Comprimento total 10,20/10,70; largura da cabeça 2,12/2,20; largura do pronoto 3,12/3,32.

Holótipo macho (Fig. 3). Cabeça, ápice do rostro, mesotórax inferiormente, castanho-escuros, quase pretos; pronoto, escutelo, tórax inferiormente, pernas, abdômen, castanho-avermelhados; tégminas castanho-escuras, com uma larga faixa mediana esbranquiçada, ocupando aproximadamente um terço da área total, com alguns pontos escuros entre as veias; venação pouco distinta. Pigóforo (Fig. 15) com os processos látero-posteriores digitiformes, alongados, curvados para baixo; placa subgenital bipartida, cada metade terminada em ponta aguda, tendo no bordo externo, três espinhos enfileirados, o basal mais robusto, os demais diminutos; processos basais longos, afilados, pontiagudos, ligeiramente curvos para cima perto do ápice; parâmeros (Figs. 16-17) robustos, bilobados distalmente: lobo interno digitiforme, longo, aproximadamente cinco vezes mais longo que largo basalmente; 
lobo externo curto, curvado para baixo e para dentro, pontiagudo, fortemente pigmentado; edeago (Fig. 18) bífido, o ramo anterior afilado distalmente, o ramo posterior mais curto, afastado e divergente para o ápice.

Fêmea. Semelhante ao macho, em geral mais escura, com a porção clara mediana das tégminas menos definida.

Material examinado. Holótipo macho de "Ecuador: Napo, Baeza/ 1222.II.1983/ leg. L. Huggert", (LUND). Parátipos: 3 fêmeas e 17 machos com os mesmos dados do holótipo (LUND; DZUP).

Comentários. Esta espécie se distingue das demais, pela presença de apenas uma faixa clara mediana nas tégminas; esta faixa ocupa aproximadamente todo o terço médio, em geral bem contrastada nos machos enquanto que, nas fêmeas, a faixa é difusa e pouco delimitada. $\mathrm{O}$ edeago apresenta o ramo posterior divergente para o ápice.

Etimologia. O nome específico é alusivo à presença de apenas uma faixa nas tégminas.

\section{Sphenorhina pichita sp.n.}

Figs 4, 19-21

Diagnose. Coloração geral vermelho-acastanhada; tégminas castanho-escuras, com o terço basal e uma faixa transversal no terço apical, alaranjados. Placa subgenital com cinco dentículos nas margens externas perto do ápice; parâmeros com o lobo externo quadrangular e bi-denticulado.

Medidas em milímetros, macho. Comprimento total 11,00; largura da cabeça 2,20; largura do pronoto 3,30 .

Holótipo macho (Fig. 4). Cabeça, pronoto, escutelo e pernas vermelho-acastanhados; tórax inferiormente e abdômen enegrecidos com margens dos escleritos avermelhadas; tégminas castanho-escuras, sendo alaranjados o terço basal (com pequenas interrupções entre a margem costal e a R, e ao longo da $\mathrm{R}$ e da $\mathrm{M}$ ) e a faixa transversal estreita na altura do ápice do clavo; reticulado apical saliente. Pigóforo (Fig. 19) com processos látero-posteriores alongados, pontiagudos, curvados para cima e para dentro; placa subgenital bipartida, com os processos basais bem desenvolvidos, pontiagudos, levemente curvados para dentro; cada metade afilada distalmente e provida na margem externa, próximo ao ápice, de uma fileira simples de cinco pequenos espinhos; parâmeros (Fig. 20) bilobados distalmente: o lobo interno digitiforme, curvado para fora, com o ápice ligeiramente dilatado e rombo; o lobo externo curto, mais ou menos quadrangular e terminado em dois dentículos, o basal um pouco maior; edeago (Fig. 21) bífido, vertical, aproximadamente retilíneo: o ramo anterior mais longo, gradativamente afilado para o ápice, o ramo posterior delgado, estiliforme, mais ou menos paralelo e pouco afastado do anterior.

Fêmea. Desconhecida.

Material examinado. Holótipo macho de "C[entral]-PERU: [Mina] Pichita/ Caluga, 2200m, hoya/del río Chanchamayo,/ 27.VI.1959/ leg. W. Weyrauch" "ex-col/ Weyrauch" "COLECCION/ Fundación M. Lillo/ 4000 S.M. Tucumán/ TUCUMAN-ARGENTINA", (IMLA). Parátipo: 1 macho com os mesmos dados do holótipo, (MCPU). 


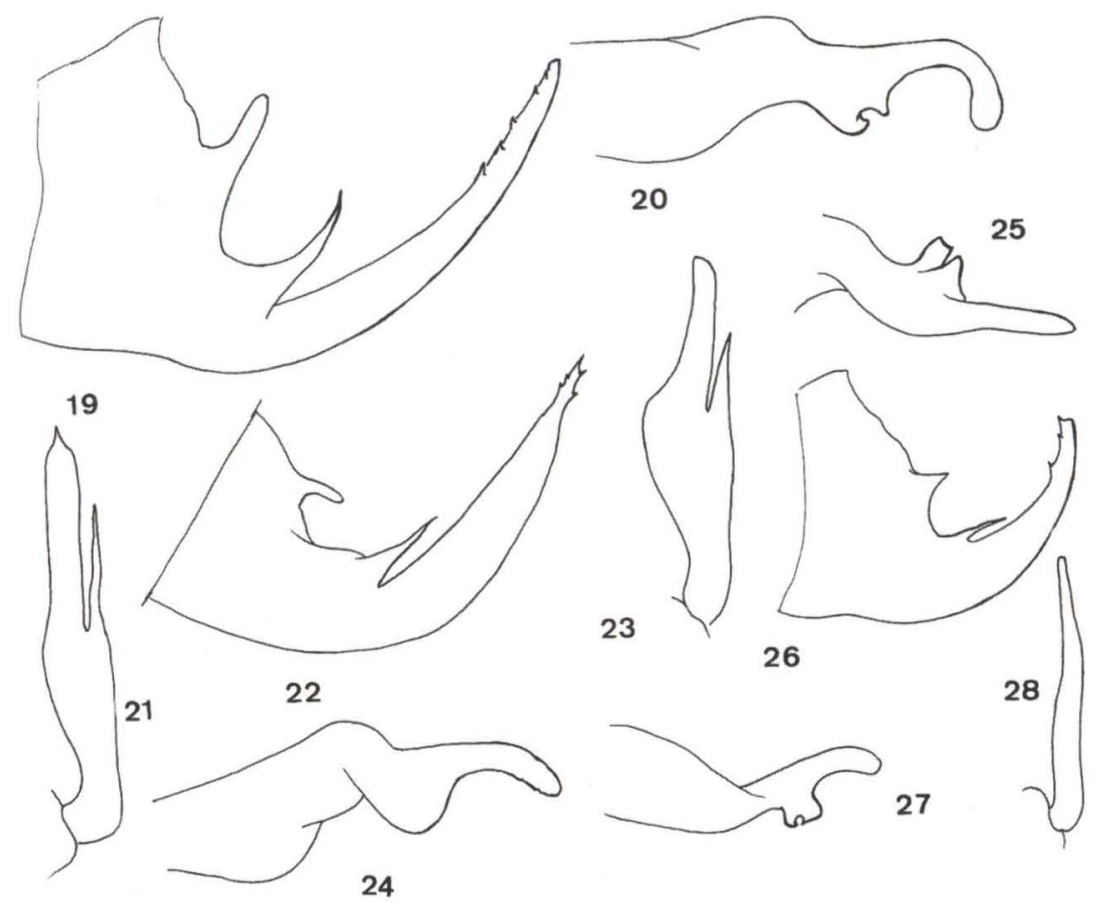

Figs 19-28. Genitálias dos holótipos. (19-21) S. pichita: (19) pigóforo; (20) ápice do parâmero esquerdo; (21) edeago. (22-25) S. badia: (22) pigóforo; (23) edeago; (24-25) ápice do parâmero esquerdo, em duas vistas. (26-28) S. rubrolurida: (26) pigóforo; (27) ápice do parâmero esquerdo; (28) edeago.

Comentários. Esta espécie difere das outras por apresentar o vértice profundamente sulcado látero-externamente aos ocelos, evidenciando a elevação média. O pronoto é grosseiramente pontuado. As tégminas são escuras com faixas transversais alaranjadas; a faixa basal pode se alargar tomando quase todo o terço basal; a faixa posterior mais estreita, ligeiramente alargada para a margem costal. A genitália, no aspecto geral, é parecida com a de S. danielssoni sp.n..

Etimologia. $\mathrm{O}$ nome específico é o mesmo da localidade-tipo, em aposição.

\section{Sphenorhina badia sp.n.}

Figs 5, 22-25

Diagnose. Coloração geral vermelho-escura; tégminas acastanhadas com o terço basal e uma faixa transversal estreita no terço apical, alaranjados. Placa subgenital terminada em pequeno espinho e perto deste, 1-2 outros nas margens externas e internas.

Medidas em milímetros, macho. Comprimento total 11,00; largura da cabeça 2,16; largura do pronoto 3,20. 
Holótipo macho (Fig. 5). Cabeça, pronoto, escutelo, tórax inferiormente, pernas e abdômen, vermelho escuro, sanguíneo; último artículo do rostro, tarsos e parte do abdômen, enegrecidos; tégminas castanho-claras: o terço basal e uma faixa transversal estreita no terço apical, na altura do ápice do clavo, vermelho-alaranjados; venação pouco distinta, com a porção reticulada contrastada com o fundo escuro. Pigóforo (Fig. 22) com os processos látero-posteriores relativamente curtos, digitiformes, ligeiramente curvados para dentro e para baixo; placa subgenital bipartida, com processos basais bem desenvolvidos, pontiagudos; cada metade abruptamente afilada perto do ápice e terminada em pequeno espinho, e perto deste, outros 1-2 dispostos nas margens interna e externa; parâmeros (Figs. 24-25) bilobados apicalmente: o lobo interno digitiforme, curvado para fora, com ápice rombo; o lobo externo curto, voltado para baixo e terminado em dois pequenos dentes, o basal um pouco maior; edeago (Fig. 23) bífido, vertical, expandido medianamente e abruptamente afilado para o ápice: o ramo anterior mais longo, obliquamente truncado no ápice; o ramo posterior delgado, espiniforme, loigeiramente divergente para o ápice.

Fêmea. Desconhecida.

Material examinado. Holótipo macho de "ECUADOR/ AZUAY/ ARENALES/ 23.II.1984/ Lg. Ernesto Martinez" (MCPU).

Comentários. É muito parecida à espécie anterior porém, o vértice é menos sulcado e o pronoto com pontuação normal. As tégminas são castanho-claras, translúcidas. A genitália lembra um pouco a de $S$. huggerti sp.n.

Etimologia. O nome específico é alusivo à coloração castanho-clara das tégminas (badius $=$ marron).

\section{Sphenorhina rubrolurida sp.n.}

Figs 6, 26-28

Diagnose. Coloração geral vermelho-clara; cabeça castanho-escura; tégminas castanho-claras com o terço basal e uma faixa transversal no terço apical, vermelho-claros. Placa subgenital com os processos basais diminutos; distalmente com três espinhos nas margens externas; edeago uni-ramoso.

Medidas em milímetros, macho. Comprimento total 9,52; largura da cabeça 1,76; largura do pronoto 2,72 .

Holótipo macho (Fig. 6). Cabeça castanho-escura, com as extremidades dos lóbulos supra-antenais, antenas, genas e rostro, avermelhados; pronoto, escutelo, tórax inferiormente, pernas e abdômen, vermelho-sanguíneos; tégminas castanhoclaras, levemente translúcidas e escurecidas no ápice, com o terço basal e uma faixa transversal estreita no terço apical, na altura do ápice do clavo, vermelho-claros; venação pouco distinta. Pigóforo (Fig. 26) com processos látero-posteriores muito curtos, aproximadamente triangulares, tão longos quanto largos na base, voltados para trás e para cima; placa subgenital bipartida, com os processos basais inconspícuos, em forma de um curto e delgado espinho: cada metade afilada distalmente, terminada em ponta romba, provida perto do ápice de três diminutos espinhos enfileirados ao longo da margem externa; parâmeros (Fig. 27) bilobados distalmen- 
te: o lobo interno digitiforme, curvado para fora, com o ápice rombo; o lobo externo curto, mais ou menos quadrangular e terminado em dois dentículos, o basal um pouco maior; edeago (Fig. 28) uni-ramoso, mais ou menos reto, dirigido obliquamente para trás, em vista lateral delgado e afilado para o ápice, em vista posterior levemente espatulado.

Fêmea. Desconhecida.

Material examinado. Holótipo macho de "Bolivia: Yungas/ del Palmar/ 2000m. IV.1948" "Schoenfelder/ 1970-450", (BMNH). Parátipo: 1 macho com os mesmos dados do holótipo, (MCPU).

Comentários. Esta espécie é de porte relativamente pequeno, com as tégminas apresentando a margem costal menos arqueada em comparação com as outras. As tégminas são acastanhadas e com um vermelho vivo no terço basal e na faixa posterior. O edeago uni-ramoso faz com que esta espécie fique deslocada com relação às demais.

Etimologia. O nome specífico é alusivo à coloração das tégminas: rubro $=$ vemelho e lurida $=$ castanho-claro.

AGRADECIMENTOS. A Roy Danielsson (LUND), Mick Webb (BMNH) e Patrício Fidalgo (IMLA), pelo empréstimo de material que permitiu o presente estudo.

\section{REFERÊNCIAS BIBLIOGRÁFICAS}

Amyot, C.J.B. \& J.G.A. Serville. 1843. Histoire Naturelle des Insectes. Hémiptères. Paris, Librairie Encyclopédique de Roret, 676p.

FennaH, R.G. 1949. New Genera and Species of Neotropical Cercopoidea (Homoptera). Ann. Mag. Nat. History 1 (12): 605-620.

. 1968. Revisionary notes on the New World Genera of Cercopid Froghoppers (Homoptera: Cercopoidea). Bull. Entomol. Res. 58: 165-190.

Recebido em 22.I.1999; aceito em 16.XI.1999. 